\title{
Effects of aerobic exercise on blood pressure and lipids in overweight hypertensive postmenopausal women
}

\author{
Tarek Ammar* \\ Faculty of Physical Therapy, Cairo University, Cairo, Egypt
}

Menopause may increase risk of hypertension and abnormal lipid profile. The aim of the study was to examine the effects of morning and afternoon aerobic exercises on hypertension and lipids in overweight hypertensive postmenopausal women. Forty five women aged from 49 to 60 years were randomly assigned into three groups. Group $(A) 15$ patients received medicine, $(B) 15$ patients performed morning aerobic exercises and received medicine, and group (C) 15 patients performed afternoon aerobic exercises and received medicine. Blood pressure measurement and lipid profile tests were performed before and after the study. The results showed that there was a statistical significant difference among all groups in systolic and diastolic blood pressure, favoring group $\mathrm{C}$. Also there was a statistical significant difference among all groups in lipid levels, favoring group C. Therefore, it can be concluded that morning aerobic exercises were more effective in reducing the blood pressure and lipids than afternoon exercises in overweight hypertensive postmenopausal women.

Keywords: Aerobic exercise, menopause, hypertension, lipids

\section{INTRODUCTION}

Menopause is defined as permanent termination of the primary functions of the ovaries, release of ova and hormones that causes uterine lining and shedding (Staessen et al., 2001). The average age of menopause is $51 \mathrm{yr}$ (te Velde and Pearson, 2002).

Hypertensive drugs are usually prescribed to control hypertension. Diuretics and $\beta$-blockers are usually used in uncomplicated hypertension. Calcium channel blockers and angiotensin-converting enzyme inhibitors are also listed as first-line drugs. Menopause results in vasomotor changes, urogenital atrophy changes, psychological changes, insomnia. Menopause may increase risks of cardiovascular disease, osteoporosis, abnormal lipid profile, and overweight (Al-Safi and Polotsky, 2015; Saha et al. 2013;). Conti et al. (2014) postulated a sharp increase of hypertension and metabolic dysfunctions after menopause.

Hypertension is the most important risk factor that affects women in the early postmenopausal years (Yanes and Reckelhoff, 2011). Blood pressure surges in the early postmenopausal years
(Kim et al., 2014). Kim and associates (2014) showed that uncontrolled hypertension ( $>140 / 90 \mathrm{mmHg}$ ) had increased from $5.06 \%$ in the postmenopausal women in their forties to 10.72 $12.36 \%$ in those women over 50 . Kearney et al. (2005) estimated that 130 million western women has uncontrolled hypertension, and that number will increase to approximately 160 million in the next two decades.

Aerobic exercises, aquatic exercises and relaxation are non-pharmacological methods used to control hypertension in overweight hypertensive postmenopausal women (Arca et al., 2014; Saensak et al., 2013; Swift et al., 2012). Petriz et al. (2015) reported that low intensity exercises reduced systolic blood pressure in rats. Moderate-intensity aerobic exercise (40-70\% maximal oxygen consumption) is associated with a significant reduction of blood pressure in hypertensive, normotensive, overweight and normal weight participants (Whelton, 2002).

Regular aerobic exercises have also been shown to improve lipid profile abnormalities and endothelial function (Swift et al., 2012; Wagner et al., 2015). Sessa et al. (1994) showed that aerobic exer-
${ }^{*}$ Corresponding author: Tarek Ammar

Faculty of Physical Therapy, Cairo University, 7 Ahmed Elzaiat St. Ben Elsary, EI Dokki, Giza, Egypt 12612

Tel: +202-37617693, Fax: +202-37617692, E-mail: tarekphysical@yahoo.com Received: May 3, 2015 / Accepted: June 10, 2015
This is an Open Access article distributed under the terms of the Creative Commons Attribution Non-Commercial License (http://creativecommons.org/licenses/by-nc/3.0/) which permits unrestricted non-commercial use, distribution, and reproduction in any medium, provided the original work is properly cited. 
cise stimulates nitric oxide and prostaglandin release. Exercises also reduced free radical-mediated nitric oxide degradation, sympathetic vasoconstrictor tone and blood pressure (Hinderliter, 2002; Niebauer and Cooke, 2006; Salhotra et al., 2009).

Blood pressure surges steadily during the day and dips nocturnally showing a circadian rhythm (García-Ortiz et al., 2014). However, many hypertensive patients exhibit circadian disturbances in their blood pressure rhythm (Masuki et al., 2005). Some authors such as Park et al. (2005) showed a relationship between time of day for exercise and reduction in blood pressure. They found that evening exercises reduced the blood pressure more than morning exercise. The purpose of the study was to determine the effect of diurnal variation of aerobic exercise on hypertension and lipid profile in overweight hypertensive postmenopausal women.

\section{MATERIALS AND METHODS}

\section{Design}

This was a randomized trial with participants randomly assigned to one of three groups: (1) group A received hypertensive medications (2) group B received hypertensive medications and morning aerobic exercises and (3) group $C$ received hypertensive medications and afternoon aerobic exercises. The tester made group comparisons at the initial visit and three months follow-up. The duration of intervention was 12 weeks per participant, and each participant in group $\mathrm{B}$ and $\mathrm{C}$ received three sessions per week.

\section{Participants}

Forty-five overweight hypertensive postmenopausal women who met the inclusion criteria were recruited from a gynecologic clinic. A physician examined the women to establish their diagnosis. Inclusion criteria included age between 49 and $60 \mathrm{yr}$, blood pressure range from $140 / 90 \mathrm{mmHg}$ to $<160 / 100 \mathrm{mmHg}$ and BMI ranged from 25 to $31 \mathrm{~kg} / \mathrm{cm}^{2}$.

Reasons for the exclusion criteria included those with cardiopulmonary disease, neurological dysfunction, liver disorders, auto immune diseases, diabetes mellitus, renal disorders and those with surgical menopause. All patients were at least two years post menopause. The study was conducted during the period from September to December 2014. All subjects signed a consent form permitting the use of their data for research purposes, and confidentiality was assured by the use of an anonymous coding system. Participants were asked to refrain from other forms of physical therapy during the study.

\section{Instrumentation}

The researcher used a weight and height scale to measure body mass index before start of the study. The tester also used a mercury sphygmomanometer (Model TXJ-10, Japan) to measure systolic blood pressure (SBP) and diastolic blood pressure (DBP) of each woman before and after end of the study. Lipid profile tests were used to measure level of high density lipoproteins (HDL), low density lipoproteins (LDL), triglycerides (TG) and total cholester$\mathrm{ol}$ (TC) before and after the study.

Measurement of blood pressure was performed for each participant before starting the study and after its end. Each participant was asked to assume long sitting position, the rubber cuff of the sphygmomanometer was wrapped around the upper arm and a stethoscope was placed over the brachial artery. The rubber cuff was inflated with the air. As the air in the cuff was released, the first sound heard marked the systolic pressure. As the release of air from the cuff persisted, the point where the sound disappeared marked the diastolic pressure. The tester took the average of two blood pressure measurements.

The lipid profile tests included measurements of HDL, LDL, TG, and TC. The test was performed for each patient before starting the study and after its end. The blood analysis required a 12-h fast. A blood sample of three centimeters was obtained by inserting a needle into a vein in the arm.

Electronic treadmill (DX12-DKB) was used to exercise the participants. It included a large display consisting of liquid crystal display feedback screen, time (minutes), distance (kilometers), speed (hertz), calories (kilocalories), pulse (beats/min), and on/off button. Deck type was ultimate hard-wax reversible deck with running area of $60 \times 20$ inches. The height of the deck step was 7.5 inches. The device also included the ultimate deck cushioning system, contact heart rate sensors telemetric and heart rate receiver. The motor was of 1.5 horse power. Speed ranged from 0.80 to 18.00 kilometer per hour.

\section{Procedure}

Participants who met the inclusion criteria were randomly assigned to one of three groups. Randomization was done by a computer generated random table. Only one independent investigator, blinded to group allocation, conducted the testing procedures at the baseline, and three months follow up. Participants were randomly divided into three groups: Group A participants received antihypertensive medication (angiotensin-converting enzyme inhibitors) once daily for three months. Group B participants performed morning aerobic exercises $(9.00-11.00 \mathrm{am})$ for $30 \mathrm{~min}$ 
three days per week for three months and received antihypertensive medication (angiotensin-converting enzyme inhibitors) once daily for three months. Group $C$ participants performed afternoon aerobic exercises (16.00-18.00 pm) for $30 \mathrm{~min}$, three days per week for three months and received antihypertensive drug (angiotensin-converting enzyme inhibitors) once daily for 3 months.

\section{Exercise program}

The aerobic exercises were walking on the treadmill for $30 \mathrm{~min}$ including three phases. Warming-up phase which consisted of walking on the treadmill for five minutes, with low intensity ( $40 \%$ of Maximum Heart Rate, MHR), actual phase which consisted of walking on the treadmill for 20 min with moderate intensity (60-75\% of MHR) and Cooling phase which consisted of walking on the treadmill for five minutes with low intensity ( $40 \%$ of MHR). MHR was calculated according to the equation (210age in years). The frequency of exercise was three times per week for three months. During the training session, the therapist stood near the patient to observe and detect signs of stopping the exercise as dexterity. The therapist continuously asked the patient if she felt pain, dizzy or shortens of breath.

The therapist advised all participants to drink a plenty of water before and after the exercise session to avoid excessive loss of body water during the session. Each patient was instructed to wear comfortable clothes and flat light shoes.

\section{Statistical analysis}

Data analysis was performed by using SPSS for Windows. One way analysis of variance test was used for multiple group comparisons. Paired t-test was used to compare between pre-test and posttest treatment.

\section{RESULTS}

The mean values and standard deviation (SD) of physical characteristics (age, weight, height and body mass index) of all 45 participants in groups $\mathrm{A}, \mathrm{B}$, and $\mathrm{C}$ are shown in Table 1 . There

Table 1. Mean values of physical characteristics of groups $A, B$, and $C$

\begin{tabular}{lrrrrr}
\hline \multirow{2}{*}{ Items } & \multicolumn{1}{c}{ Group A } & \multicolumn{1}{c}{ Group B } & Group C & $\begin{array}{c}F \\
\text { value }\end{array}$ & $\begin{array}{c}P \text { - } \\
\text { value }\end{array}$ \\
\cline { 2 - 4 } & Mean \pm SD & Mean \pm SD & Mean $\pm S D$ & & \\
\hline Age $(\mathrm{yr})$ & $53.24 \pm 1.82$ & $53.24 \pm 1.94$ & $52.13 \pm 1.85$ & 0.728 & 0.629 \\
Weight $(\mathrm{kg})$ & $81.60 \pm 5.16$ & $83.17 \pm 5.74$ & $85.78 \pm 5.22$ & 0.513 & 0.731 \\
Height $(\mathrm{cm})$ & $167.63 \pm 2.01$ & $166.72 \pm 1.62$ & $167.90 \pm 1.78$ & 0.148 & 0.916 \\
BMl $\left(\mathrm{kg} / \mathrm{m}^{2}\right)$ & $29.01 \pm 0.73$ & $28.92 \pm 1.13$ & $29.82 \pm 1.12$ & 1.747 & 0.182 \\
\hline
\end{tabular}

were not statistically significant differences among the three groups as shown in the Table 1.

\section{Measurement of blood pressure Systolic blood pressure}

The mean values, SD and percentage of improvement of SBP pre and post treatment for all groups are shown in Table 2. For pretreatment values, there was not statistically significant differences between the mean values of SBP of the three groups $(P=0.6)$. For post-treatment values, there was statistically significant difference between the mean value of SBP of the three groups $(P=0.001)$. Also, the mean value of SBP was significantly decreased in group $\mathrm{C}$ when compared to group $\mathrm{B}(P=0.04)$.

\section{Diastolic blood pressure}

The mean values, SD and percentage of improvement of DBP pre and post treatment for all groups are shown in Table 3. For pre-treatment values, there was not statistically significant difference between the mean values of DBP of all groups. For post treatment, there was a statistically significant difference between the mean value of DBP of all groups $(P=0.001)$. Least significant difference test showed a statistically significant decrease in the mean value of DBP of both groups $B$ and $C$ when compared to group A. Also, the mean value of DBP was significantly decreased in group $\mathrm{C}$ when compared to group $\mathrm{B}(P=0.018)$.

\section{Lipid profile tests}

\section{High density lipoprotein (HDL)}

The mean values, SD and percentage of improvement of HDL

Table 2. Mean values of SBP measured pre and post treatment in groups $A, B$, and $\mathrm{C}$

\begin{tabular}{|c|c|c|c|c|c|}
\hline & \multirow{2}{*}{$\begin{array}{c}\text { Pre treatment } \\
\text { Mean } \pm \text { SD }\end{array}$} & \multirow{2}{*}{$\frac{\text { Post treatment }}{\text { Mean } \pm \text { SD }}$} & \multirow{2}{*}{$\begin{array}{l}\text { Percentage of } \\
\text { improvement } \%\end{array}$} & \multirow{2}{*}{ t-value } & \multirow{2}{*}{$P$-value } \\
\hline & & & & & \\
\hline Group A & $154.21 \pm 7.91$ & $146.63 \pm 7.01$ & 3.67 & 7.500 & 0.001 \\
\hline Group B & $151.00 \pm 7.34$ & $138.33 \pm 6.70$ & 8.02 & 10.127 & 0.001 \\
\hline Group C & $153.43 \pm 7.89$ & $126.13 \pm 6.30$ & 9.60 & 11.651 & 0.001 \\
\hline
\end{tabular}

Table 3. Mean values of DBP measured pre and post treatment in groups $A, B$, and $\mathrm{C}$

\begin{tabular}{lcccccc}
\hline & Pre treatment & & Post treatment & $\begin{array}{c}\text { Percentage of } \\
\text { improvement \% }\end{array}$ & t-value & $P$-value \\
\cline { 2 - 3 } & Mean \pm SD & & Mean \pm SD & & \\
\hline Group A & $92.61 \pm 4.32$ & & $88.43 \pm 3.62$ & 3.74 & 4.685 & 0.001 \\
Group B & $93.10 \pm 4.52$ & & $81.66 \pm 5.71$ & 11.65 & 14.241 & 0.001 \\
Group C & $94.21 \pm 4.36$ & & $78.80 \pm 3.38$ & 16.31 & 15.019 & 0.001 \\
\hline
\end{tabular}


Table 4. Mean values of HDL measured pre and post treatment in groups $A, B$, and C

\begin{tabular}{|c|c|c|c|c|c|}
\hline & \multirow{2}{*}{$\begin{array}{c}\text { Pre treatment } \\
\text { Mean } \pm \text { SD }\end{array}$} & \multirow{2}{*}{$\frac{\text { Post treatment }}{\text { Mean } \pm \text { SD }}$} & \multirow{2}{*}{$\begin{array}{l}\text { Percentage of } \\
\text { improvement \% }\end{array}$} & \multirow{2}{*}{$\mathrm{t}$-value } & \multirow{2}{*}{$P$-value } \\
\hline & & & & & \\
\hline Group A & $46.73 \pm 7.61$ & $49.53 \pm 7.89$ & -6.69 & -4.620 & 0.001 \\
\hline Group B & $47.24 \pm 4.41$ & $54.27 \pm 2.84$ & -17.29 & -7.624 & 0.001 \\
\hline Group C & $42.36 \pm 4.74$ & $56.53 \pm 4.19$ & -29.96 & -16.336 & 0.001 \\
\hline
\end{tabular}

Table 5. Mean values of LDL measured pre and post treatment in groups $A, B$, and C

\begin{tabular}{|c|c|c|c|c|c|}
\hline & \multirow{2}{*}{$\begin{array}{c}\text { Pretreatment } \\
\text { Mean } \pm S D\end{array}$} & \multirow{2}{*}{$\frac{\text { Post treatment }}{\text { Mean } \pm S D}$} & \multirow{2}{*}{$\begin{array}{l}\text { Percentage of } \\
\text { improvement \% }\end{array}$} & \multirow{2}{*}{ t-value } & \multirow{2}{*}{$P$-value } \\
\hline & & & & & \\
\hline Group A & $148.47 \pm 34.96$ & $123.62 \pm 41.02$ & 8.93 & 5.716 & 0.001 \\
\hline Group B & $152.30 \pm 31.38$ & $124.53 \pm 22.67$ & 16.71 & 7.653 & 0.001 \\
\hline Group C & $147.27 \pm 16.77$ & $111.23 \pm 8.94$ & 27.01 & 8.241 & 0.001 \\
\hline
\end{tabular}

pre and post-treatment for all groups are shown in Table 4. For pretreatment values, there was not statistical significant difference between the mean value of HDL of all groups $(P=0.085)$. For post-test values, there was statistical significant difference between the mean value of HDL of the three groups $(P=0.01)$, favoring group $C$. Least significant difference test showed a statistically significant increase in the mean value of $\mathrm{HDL}$ of group $\mathrm{C}$ when compared to group A $(P=0.004)$. There was statistical significant difference between groups $\mathrm{B}$, and $\mathrm{A}(P=0.02)$. On the other hand, there was no statistical significant difference in the mean value of $\mathrm{HDL}$ between groups $\mathrm{C}$ and $\mathrm{B}(P=0.5)$.

\section{Low density lipoprotein (LDL)}

The mean values, SD and percentage of improvement of LDL pre and post treatment for all groups are shown in Table 5. For pretreatment values, there was not statistical significant difference between the mean value of $\mathrm{LDL}$ of groups $\mathrm{A}, \mathrm{B}$ and $\mathrm{C}(P=0.992)$. The mean value of LDL post treatment was found to be significantly decreased in all groups $(P=0.04)$, favoring group $C$. Least significant difference test showed a statistical significant decrease in the mean value of $\mathrm{LDL}$ of group $\mathrm{C}$ when compared to group $\mathrm{A}$ $(P=0.01)$. On the other hand, there was not statistical significant difference in the mean value of LDL between groups $A$ and $B$ $(P=0.4)$ and at the same time between groups $\mathrm{B}$ and $\mathrm{C}(P=0.09)$.

\section{Triglycerides (TG)}

The mean values, SD and percentage of improvement of TG pre and post treatment for all groups are shown in Table 6. For pre-treatment values, there was not statistical significant differ-
Table 6. Mean values of TG measured pre and post treatment in groups A, B, and $\mathrm{C}$.

\begin{tabular}{lccccrc}
\hline & Pre treatment & & Post treatment & $\begin{array}{c}\text { Percentage of } \\
\text { improvement \% }\end{array}$ & t-value & $P$-value \\
\cline { 2 - 3 } & Mean \pm SD & & Mean $\pm S D$ & & \\
\hline Group A & $238.21 \pm 41.65$ & & $235.20 \pm 43.91$ & 0.96 & 8.132 & 0.001 \\
Group B & $261.87 \pm 40.11$ & & $214.61 \pm 38.01$ & 19.45 & 18.671 & 0.001 \\
Group C & $230.80 \pm 38.25$ & & $198.61 \pm 33.25$ & 17.13 & 12.115 & 0.001 \\
\hline
\end{tabular}

Table 7. Mean values of cholesterol measured pre \& post treatment in groups $A, B$, and $C$

\begin{tabular}{|c|c|c|c|c|c|}
\hline & \multirow{2}{*}{$\frac{\text { Pre treatment }}{\text { Mean } \pm S D}$} & \multirow{2}{*}{$\frac{\text { Post treatment }}{\text { Mean } \pm S D}$} & \multirow{2}{*}{$\begin{array}{l}\text { Percentage of } \\
\text { improvement \% }\end{array}$} & \multirow{2}{*}{ t-value } & \multirow{2}{*}{$P$-value } \\
\hline & & & & & \\
\hline Group A & $240.20 \pm 36.32$ & $227.30 \pm 41.39$ & 7.57 & 7.782 & 0.001 \\
\hline Group B & $246.23 \pm 27.78$ & $223.13 \pm 20.36$ & 12.22 & 8.720 & 0.001 \\
\hline Group C & $237.20 \pm 24.37$ & $202.40 \pm 14.16$ & 18.28 & 8.610 & 0.001 \\
\hline
\end{tabular}

ence between the mean values of TG of the three groups $(P=0.06)$. For posttest values, there was statistical significant difference between the mean values of TG in the three groups $(P=0.01)$, favoring group B. Least significant difference test showed a statistically significant difference in the mean value of TG of group $C$ when compared to group A $(P=0.003)$. On the other hand, there was not statistical significant difference in the mean value of TG between groups $\mathrm{A}$ and $\mathrm{B}(P=0.1)$ and at the same time between groups $\mathrm{B}$ and $\mathrm{C}(P=0.1)$.

\section{Cholesterol}

The mean values, $\mathrm{SD}$ and percentage of improvement of cholesterol pre and post treatment for all groups are shown in Table 7 . For pretreatment values, there was not statistical significant difference between the mean value of cholesterol of all groups $(P=0.5)$. For posttest, the mean value of cholesterol post treatment was found to be significantly decreased in the three groups favoring of group $C$. There was statistical significant difference between the mean value of cholesterol in all groups $(P=0.04)$. LSD test showed a statistical significant difference in the mean value of cholesterol of group $C$ when compared to groups $A$ $(P=0.02)$ and group B $(P=0.04)$. On the other hand, there was not statistical significant difference in the mean value of cholesterol between groups $\mathrm{A}$ and $\mathrm{B}(P=0.7)$.

\section{DISCUSSION}

The results of this study showed a statistical significant difference between the mean values of SBP, DBP, HDL, LDL, TG, and 
cholesterol in groups A, B, and C. The results of the current study showed that women who exercised in the afternoon showed the most significant statistical difference compared with those who exercised in the morning or received medications. The percentage of improvements was $30.97 \%$ in group C compared to $5.99 \%$ in group A and $17.29 \%$ in group B. The results of this study should be carefully interpreted as results vary by cooperation of patients, individual responses, health status of each patient and variability of patients and their reaction.

The results of the current study are supported with study of Park et al. (2005) who reported that afternoon exercise exhibited a greater reduction in SBP. The results of this study agreed with the study of Jones et al. (2006) that reported that blood pressure is normally reduced after a bout of exercise, but this post-exercise hypotension may be absent or reversed with morning exercises. The results of the current study also agreed with Jones et al. (2008) who confirmed that the acutely hypotensive effects following $30 \mathrm{~min}$ of continuous exercises are less substantial in the morning, probably because the exercise-mediated decrease in peripheral resistance is not as apparent at this time of day.

These results are supported by the findings of Havelkov et al. (2007) who found that systolic and diastolic pressures significantly increased in patients who underwent morning exercise training and significantly decreased in those who did their exercises in the afternoon. This shows that the time of exercises influences the average value of blood pressure during the circadian cycle.

The results of this study also agreed with Jones et al. (2009) who concluded that afternoon exercises with interrupted rest periods reduced blood pressure more than continuous exercises. Findings of this study is also similar to those of Tibana et al. (2013) who found decrease of SBP and DBP post resistance exercise in the nighttime in overweight and obese middle-aged women.

Findings of this study agreed with Leon and Sanchez (2001) who reported that moderate or vigorous aerobic exercise improved the blood lipid profile. Results of this study are also similar to those of Roberts (2002) who showed that regular exercises and dietary alterations decreased oxidative stress, increase nitric oxide availability and improved the overall metabolic profile.

These results are supported by Trejo-Gutierrez and Fletcher (2007) who concluded that exercise exerted an effect on HDL-C maturation and composition, cholesterol efflux, and cholesterol delivery to receptors (reverse cholesterol transport). Positive effects of exercise were also seen with blood TG, but little specific effect was seen on LDL-C and total cholesterol. Also, results of this study came in consistency with Ghahramanloo et al. (2009) who reported that aerobic exercises improved the serum lipid profile and body composition of sedentary healthy young men. Results of this study were also supported by the findings of Wagganer et al. (2015) who demonstrated aerobic exercises increased HDL and lowered LDL, TG, and TC in 12 young overweight adults. Therefore, it could be concluded that aerobic exercises done in the afternoon was more effective in lowering the blood pressure and improving lipid profile than that performed in the morning in hypertensive overweight postmenopausal women.

There are a number of potential biases that could threaten the validity or the conclusions and for these reasons future investigation remains necessary in order to better understand the clinical value of the aerobic exercises in the management of hypertension and abnormal lipid profile in hypertensive overweight postmenopausal women. Perhaps the biggest limitation of this study relates to small sample size. Moreover, participants may have received other medications and other forms of physical therapy that may influence the results of this study. More studies are needed about different exercise approaches on preventing or treating other postmenopausal symptoms.

\section{CONFLICT OF INTEREST}

No potential conflict of interest relevant to this article was reported.

\section{REFERENCES}

Al-Safi ZA, Polotsky AJ. Obesity and menopause. Best Pract Res Clin Obstet Gynaecol 2015;29(4):548-553.

Arca EA, Martinelli B, Martin LC, Waisberg CB, Franco RJ. Aquatic exercise is as effective as dry land training to blood pressure reduction in postmenopausal hypertensive women. Physiother Res Int 2014;19(2): 93-98.

Conti FF, Brito Jde O, Bernardes N, Dias Dda S, Sanches IC, Malfitano C, Llesuy SF, Irigoyen MC, De Angelis K. Cardiovascular autonomic dysfunction and oxidative stress induced by fructose overload in an experimental model of hypertension and menopause. BMC Cardiovasc Disord 2014;14:185.

García-Ortiz L, Recio-Rodríguez JI, Puig-Ribera A, Lema-Bartolomé J, Ibáñez-Jalón E, González-Viejo N, Guenaga-Saenz N, Agudo-Conde C, Patino-Alonso MC, Gomez-Marcos MA; EVIDENT Group. Blood pressure circadian pattern and physicalexercise assessment by accelerometer and 7-day physical activity recall scale. Am J Hypertens 2014;27(5):665-673. 
Ghahramanloo E, Midgley A, Bentley D. The effect of concurrent training on blood lipid profile and anthropometrical characteristics of previously untrained men. J Phys Act Health 2009;6(6):760-766.

Havelkov A, Siegelov A, Fiser B, Mifkova V, Chludilova J, Pochmonov A, Halberg F. Circadian variation blood pressure variability and exercise therapy. Scr Med (Brno) 2007;80(5):191-196.

Hinderliter A. Reduction of left ventricular hypertrophy after exercise and weight loss in overweight patients with mild hypertension. Arch. Intern. Med 2002;162:1333-1339.

Jones H, Atkinson G, Leary A, George K, Murphy M, Waterhouse J. Reactivity of ambulatory blood pressure to physical activity varies with time of day. Hypertension 2006;47:778-784.

Jones H, Pritchard C, George K, Edwards B, Atkinson G. The acute post-exercise response of blood pressure varies with time of day. Eur J Appl Physiol 2008;104:481-489.

Jones H, Taylor CE, Lewis NC, George K, Atkinson G. Post-exercise blood pressure reduction is greater following intermittent than continuous exercise and is influenced less by diurnal variation. Chronobiol Int 2009;26(2):293-306.

Kearney PM, Whelton M, Reynolds K, Muntner P, Whelton PK, He J. Global burden of hypertension: analysis of worldwide data. Lancet 2005;365(9455):217-223.

Kim JM, Kim TH, Lee HH, Lee SH, Wang T. Postmenopausal hypertension and sodium sensitivity. J Menopausal Med 2014;20(1):1-6.

Leon A, Sanchez O. Response of blood lipids to exercise training alone or combined with dietary intervention. Med Sci Sports Exerc 2001;33(6): S502-515.

Masuki S, Todo T. Nakano Y, Okamura H, Nose H. Reduced $\alpha$-adrenoceptor responsiveness and enhanced baroreflex sensitivity in Cry-deficient mice lacking a biological clock. J Physiol 2005;566(Pt 1):213-224.

Niebauer J, Cooke JP. Cardiovascular effects of exercise: role of endothelial shear stress. J Am Coll Cardiol 2006;28:1652-1660.

Otto M, Svatikova A, de Mattos Barretto R. Early morning attenuation of endothelial function in healthy humans. Circulation 2004;109:25072510.

Park S, Jastremski CA, Wallace JP. Time of day for exercise on blood pressure reduction in dipping and nondipping hypertension. J Hum Hypertens 2005;19:597-605.

Petriz BA, Almeida JA, Gomes CP, Ernesto C, Pereira RW, Franco OL. Ex- ercise performed around MLSS decreases systolic blood pressure and increases aerobic fitness in hypertensive rats. BMC Physiol 2015;15(1): $1-6$.

Roberts C. Effect of diet and exercise intervention on blood pressure, insulin, oxidative stress, and nitric oxide availability. Circulation 2002; 106:2530-2532.

Saensak S, Vutyavanich T, Somboonporn W, Srisurapanont M. Modified relaxation technique for treating hypertension in Thai postmenopausal women. J Multidiscip Health 2013;6:373-378.

Saha KR, Rahman MM, Paul AR, Das S, Haque S, Jafrin W, Mia AR. Changes in lipid profile of postmenopausal women. Mymensingh Med J 2013;22(4):706-711.

Salhotra S, Arora S, Trived S, Bhattacharjee J. Influence of menopause on biochemical markers of endothelial dysfunction-A case-control pilot study in North Indian population. Maturitas 2009;62:166-170.

Sessa W, Pritchard, K, Seyedi N. Chronic exercise in dogs increases coronary vascular nitric oxide production and endothelial cell nitric oxide synthase gene expression. Circ Res 1994;74:349-353.

Staessen J, VanHeijden-Spek J, Safar M, Den Hond E, Gasowski J, Fagard R. Menopause and the characteristics of the large arteries in a population study. J Hum Hypertens 2001;15:511-518.

Swift DL, Earnest CP, Blair SN, Church TS. The effect of different doses of aerobic exercise training on endothelial function in postmenopausal women with elevated blood pressure: results from the DREW study. Br J Sports Med 2012;46(10):753-758.

Tibana RA, Pereira GB, Navalta JW, Bottaro M, Prestes J. Acute effects of resistance exercise on 24-h blood pressure in middle aged overweight and obese women. Int J Sports Med 2013;34(5):460-464.

Trejo-Gutierrez J, Fletcher G. Impact of exercise on blood lipids and lipoproteins. J Clin Lipidol 2007;1(3):175-181.

te Velde ER, Pearson PL. The variability of female reproductive ageing. Hum Reprod Update 2002;8:141-154.

Wagganer JD, Robison CE, Ackerman TA, Davis PG. Effects of exercise accumulation on plasma lipids and lipoproteins. Appl Physiol Nutr Metab 2015;40(5):441-447.

Whelton S. Effect of aerobic exercise on blood pressure: a meta-analysis of randomized, controlled trials. Ann Intern Med 2002;136:493-503.

Yanes LL, Reckelhoff JF. Postmenopausal hypertension. Am J Hypertens 2011;24(7):740-749. 